\title{
Fire spalling sensitivity of high-performance concrete in heated slabs under biaxial compressive loading
}

\author{
Francesco Lo Monte (1D) Roberto Felicetti - Chiara Rossino
}

Received: 21 August 2018/Accepted: 18 January 2019/Published online: 25 January 2019

(C) The Author(s) 2019, corrected publication July 2020

\begin{abstract}
Explosive spalling of concrete exposed to fire consists in the violent expulsion of shards from the hot surface due to the interaction between cracking and pore pressure build-up. Fire spalling relevantly increases the overall thermal damage of a structure exposed to fire, thus leading to much higher costs in the repair intervention, and in some cases it can even jeopardize the structural stability due to loss of reinforcement protection and reduction of the bearing cross-sections. High-performance concrete is particularly sensitive to spalling phenomenon due to inherent material features, such as the unstable fracture behaviour and the low permeability (favouring high values of pore pressure). In this context, an experimental campaign has been carried out on high-performance concrete $\left(f_{\mathrm{c}} \approx 60 \mathrm{MPa}\right.$ with silico-calcareous aggregate), without or with one of three different fibre types (steel fibre, monofilament or fibrillated polypropylene fibres). Tests were performed by means of a special test setup developed at Politecnico di Milano, based on slabs $(800 \times 800 \times 100 \mathrm{~mm})$ subjected to Standard Fire at the bottom and to biaxial compressive loading in the mid-plane, while monitoring pore pressure,
\end{abstract}

F. Lo Monte $(\bowtie) \cdot$ R. Felicetti

Department of Civil and Environmental Engineering,

Politecnico di Milano, Milan, Italy

e-mail: francesco.lo@polimi.it

C. Rossino

Global Product Innovation Department, Italcementi S.p.A.

- HeidelbergCement Group, Bergamo, Italy temperature and deflection. Explosive spalling was observed in both plain concrete slabs and in one of the two slabs with steel fibre, this casting some doubts on the use of steel fibre alone against spalling. No detachment was observed when polypropylene fibre was added to the mix.

Keywords Biaxial loading - Explosive spalling · Fibre · Fire · Deflection · High-performance concrete · High temperature $\cdot$ Pore pressure $\cdot$ Slab

\section{Introduction}

Structural behaviour can be strongly affected by fire due to the decay of material properties at high temperature and the introduction of indirect actions induced by restrained thermal dilation [1]. Fortunately, concrete structures generally show a satisfactory behaviour in case of fire, owing to the low thermal diffusivity. The temperature, in fact, steeply decreases from the exposed face to the inner core, so protecting most of the section and the reinforcing bars.

In this context, explosive spalling is particularly detrimental, since the reduction of the section (due to the expulsion of shards from the exposed face) weakens the insulation capability of the concrete cover. Fire spalling consists in the sudden separation of concrete splinters from the hot surface due to the 
interaction between cracking and the build-up of pore pressure in the pores [2]. In particular, fracture tests on hot concrete under sustained pore pressure corroborate the idea that a combination of mechanical stress and pore pressure is generally needed for spalling [3, 4].

Generally speaking, spalling increases the overall thermal damage, this leading to higher costs for repair. Furthermore, when structural stability is a concern, it should be considered that explosive spalling can significantly speed up the decay of fire resistance due to the reduction of the bearing cross-section and the possible direct exposure of the rebars to the hot gases.

The full understanding of spalling phenomenon, and consequently its reliable prediction in the design phase, is made particularly difficult by the interaction of many different material and structural aspects [5].

During heating, thermal stress develops because of the steep thermal gradients, leading to tension in the cold core and compression in the hot layer. This latter fosters cracking parallel to the isothermal surfaces, locally reducing the mechanical stability. Other mesoscale processes can favour micro-cracking, such as strain incompatibility between matrix and aggregate [6]. On the other hand, pore pressure is responsible for the violent nature of spalling, because of its effects on the stability of cracks. Pressure development in the pores is caused by water vaporization, since vapour escape is constrained.

The kinetic of moisture migration induced by pressure gradients is very important in spalling development and it is mainly related to concrete permeability. In particular, moisture is pushed toward the cold core, where vapour condensation can occur due to the lower temperature [7]. In dense concrete (such as High-Performance Concrete-HPC) even water saturation in the pores can be attained and a region with very low permeability may form (the so-called moisture clog [8]). The formation of a saturated layer brings in two main effects: (a) increase of vapour pressure ahead moisture clog, vapour release being prevented, and (b) increase of pressure within moisture clog due to thermal dilation of liquid water (namely, liquid pressure [9]). Such aspect, together with the higher heat-sensitivity and brittleness, makes HPC more sensitive to spalling than Normal-Strength Concrete-NSC [7, 10].

Many of the studies conducted so far clearly show that spalling phenomenon can be effectively reduced, or even avoided at all, if polypropylene fibre is added to the mix, typically in the range $1-2 \mathrm{~kg} / \mathrm{m}^{3}$ ( $\approx 0.1-0.2 \%$ by volume). Polypropylene fibre, in fact, melts at $160-170{ }^{\circ} \mathrm{C}$ producing voids and microcracks in the cement paste $[8,11,12]$. As a consequence, smoother moisture gradients [13] and lower pressure peaks [3] are observed, and possible relaxation of thermal stress is expected [11, 14].

Even though numerical models have been developed addressing fire spalling progression in concrete, the reliable prediction of its evolution is significantly affected by several uncertainties such as the mutual interaction between pore pressure and concrete fracture behaviour (as reported in [3, 4]), and porosity and permeability variation with temperature. This makes experimental investigation often necessary.

Tests aimed at assessing concrete sensitivity to explosive spalling can be performed on different specimen geometries under different heating and loading conditions [15].

A first group of tests is based on (small-scale) unloaded prismatic or cylindrical specimens [3, 10, 13, 16-18], in which temperature and/or pressure are monitored during the test. There are also examples in which external loading is applied [19-21].

Another set of tests is generally focused on slabs or prismatic specimens under different conditions of heating and loading. In many cases heating is applied on one face only, while external loading can be applied via active or passive systems, in one [22-27] or two directions [14, 21, 22].

A third level of investigations is represented by fullscale testing. Obviously, in assessing fire spalling sensitivity of concrete, the balance between cost and representativeness should be pursued, since cost and time burden increases with testing scale.

The common evidence is that (1) relevant spalling is unlikely in small specimens when stress is caused just by thermal gradients, (2) external compression applied during heating increases spalling probability [24, 26, 28], and (3) biaxial loading conditions are more severe than uniaxial ones [28].

In order to cast some light on the effect of fibre type in fire spalling sensitivity of HPC, an experimental campaign has been launched at Politecnico di Milano, in collaboration with the Global Product Innovation Department of Italcementi S.p.A.-HeidelbergCement Group, based on unreinforced slabs subjected to heating under biaxial loading. 
The experimental investigation is based on eight slabs made of four concrete mixes $\left(f_{\mathrm{c}} \approx 60 \mathrm{MPa}\right.$, with silico-calcareous aggregate): without fibre reference mix - (1), with $2 \mathrm{~kg} / \mathrm{m}^{3}$ of monofilament (2) or fibrillated (3) polypropylene fibre, or with $40 \mathrm{~kg} / \mathrm{m}^{3}$ of steel fibre (4).

\section{Mix design and test setup}

Four concrete mixes differing only for fibre type have been studied. Cement type CEM I - 42.5 R has been used in combination with Ground Granulated Blastfurnace Slag (GGBS), as shown in Table 1 (see also [29, 30]).

Silico-calcareous aggregate with maximum size of $16 \mathrm{~mm}$ has been used and the water-to-cement ratio has been designed for a target cylindrical compressive strength at 28 days $f_{\mathrm{c}} \approx 60 \mathrm{MPa}$. In addition to the plain mix, the other three mixes contain one of the following fibre type: $2 \mathrm{~kg} / \mathrm{m}^{3}$ of monofilament polypropylene fibre $\left(L=12 \mathrm{~mm}, \emptyset_{\text {eq }}=20 \mu \mathrm{m}\right.$, extruded straight fibre treated with a surfactant agent) designed specifically to prevent concrete spalling [8], $2 \mathrm{~kg} / \mathrm{m}^{3}$ of fibrillated polypropylene fibre $\left(L=12 \mathrm{~mm}, \emptyset_{\mathrm{eq}}=48 \mu \mathrm{m}\right.$, straight fibre obtained by longitudinally cutting stripes) generally used to limit early-age shrinkage [31] or $40 \mathrm{~kg} / \mathrm{m}^{3}$ of steel fibre ( $L=35 \mathrm{~mm}, \emptyset_{\text {eq }}=550 \mu \mathrm{m}$, hooked ends). Two slabs per mix were cast.

Spalling sensitivity has been assessed on unreinforced slabs $(800 \times 800 \times 100 \mathrm{~mm})$ subjected to Standard Fire at the bottom face under biaxial membrane compression (Fig. 1). The loading system consists in a welded steel frame restraining 8 hydraulic jacks ( 2 per side) with a total capacity of $1000 \mathrm{kN}$ per axis. The horizontal furnace is powered by an activelycontrolled propane gas torch, which is able to strictly follow the prescribed heating curve.

During the test, pressure and temperature have been monitored through the thickness via embedded sensors [3] placed at the distances of 10, 20, 30, 40, 50 and $60 \mathrm{~mm}$ from the exposed face, while the flexural behaviour has been monitored through 6 Linear Voltage Displacement Transducers (LVDTs) measuring the vertical displacements at the top cold face.

Heating is applied only to the central part $(600 \times 600 \mathrm{~mm})$ of the slab, so to keep colder the perimeter in contact with the hydraulic jacks. The confining effect provided by such cold rim is kept as limited as possible by sixteen radial cuts aimed at interrupting its mechanical continuity. Further details on the main features of the test setup are reported in Lo Monte and Felicetti [14].

\section{Results and discussion}

A total of eight specimens (two per mix) was tested. Fire duration was set in the range 100-120 min in absence of spalling, otherwise heating was stopped when the slab was no more able to sustain the external biaxial compression (34-35 min). The very similar fire duration among the tests (in which spalling took place) makes it possible to compare spalling sensitivity for different concretes just in terms of onset time and final depth of spalling.
Table 1 Mix designs and main properties of the concrete mixes

\begin{tabular}{lllll}
\hline Mix designation & $70 S$ & $70 S$ PM2 & 70S PF2 & 70S SF40 \\
\hline CEM I $\left(\mathrm{kg} / \mathrm{m}^{3}\right)$ & 400 & 400 & 400 & 400 \\
GGBS $\left(\mathrm{kg} / \mathrm{m}^{3}\right)$ & 200 & 200 & 200 & 200 \\
Gravel $\left[d_{\mathrm{a}}=0-8 \mathrm{~mm}\right]\left(\mathrm{kg} / \mathrm{m}^{3}\right)$ & 860 & 860 & 860 & 860 \\
Aggregate $\left[d_{\mathrm{a}}=8-16 \mathrm{~mm}\right]\left(\mathrm{kg} / \mathrm{m}^{3}\right)$ & 699 & 699 & 699 & 699 \\
Monofilament polypropylene fibre $\left(\mathrm{kg} / \mathrm{m}^{3}\right)$ & - & 2 & - & - \\
Fibrillated polypropylene fibre $\left(\mathrm{kg} / \mathrm{m}^{3}\right)$ & - & - & 2 & - \\
Steel fibre $\left(\mathrm{kg} / \mathrm{m}^{3}\right)$ & - & - & - & 40 \\
Acrylic superplasticizer $\left(\mathrm{kg} / \mathrm{m}^{3}\right)$ & 2.76 & 2.76 & 2.76 & 2.76 \\
Water/binder ratio & 0.36 & 0.36 & 0.36 & 0.36 \\
Density $\left(\mathrm{kg} / \mathrm{m}^{3}\right)$ & 2378 & 2380 & 2380 & 2418 \\
Cylindrical compressive strength, $f_{\mathrm{c}}(\mathrm{MPa})$ & 62 & 60 & 61 & 63 \\
\hline
\end{tabular}


Fig. 1 Concrete slab and detail of the PT sensor. $P T$ pressure-temperature sensors; LVDT displacement transducers measuring the deflection; $R L 3$ rigid legs of the LVDT-holding frame

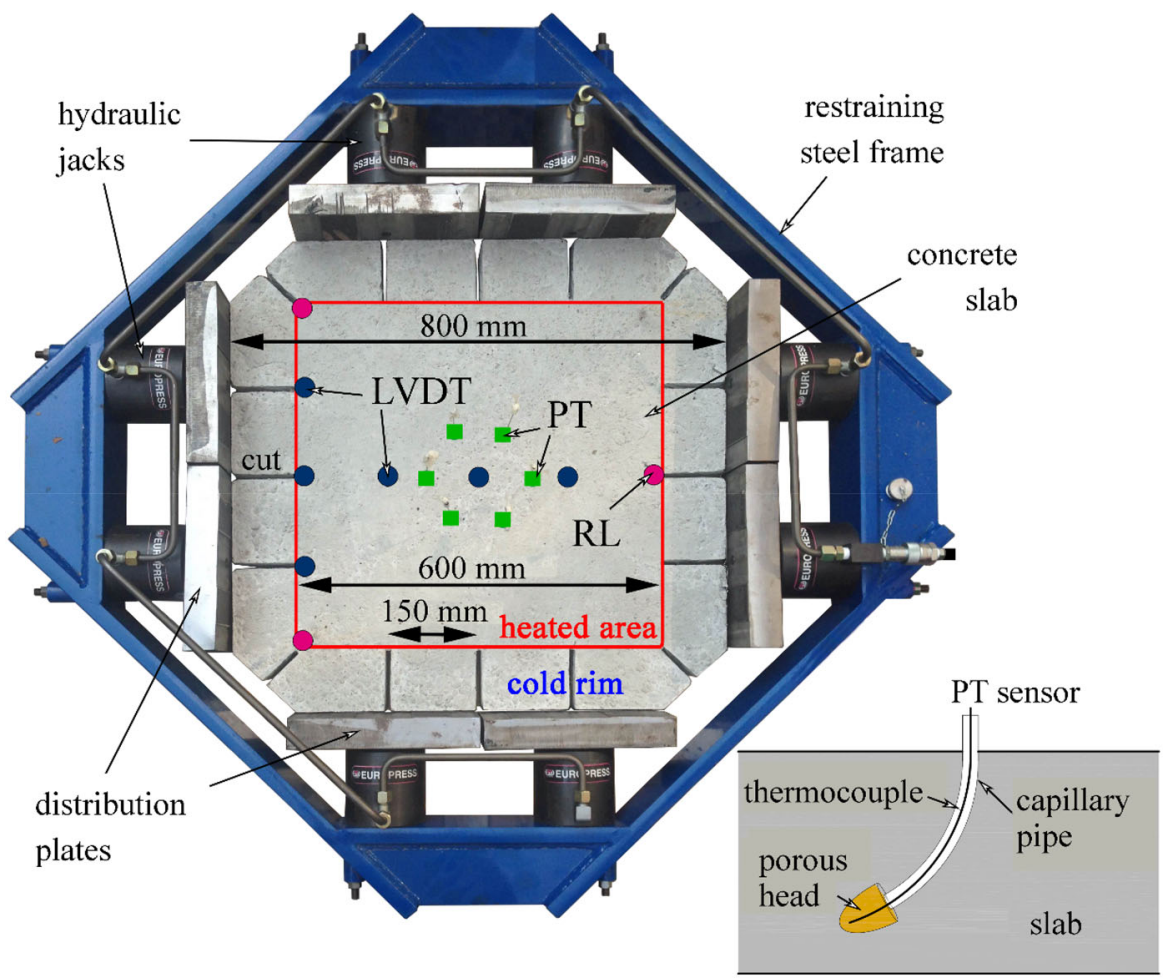

Compressive load was designed in order to instate a constant mean compressive stress in the thickness of $10 \mathrm{MPa}$ aimed at preventing the onset of tensile stress.

\subsection{Observed spalling}

Spalling occurred in both plain concrete slabs (first very severe event after 19 and 34 min for slab A and B, respectively) and only in one case for steel fibrereinforced concrete (first very severe event after $35 \mathrm{~min}$ in slab B). It is worth noting that, in all the three cases, first spalling occurred in a very violent way involving all the heated area. Only for slab A of mix M70S (plain concrete), test could be continued after the first spalling event, showing many following minor events, each one taking place in smaller but significant parts of the heated area (up to about $30 \%$ [32]) till the end of heating ( $35 \mathrm{~min}$ ). The final spalling depth was comparable among the three specimens and the spalled layer appeared rather homogeneous in the heated area. The spalled profile was measured after the test via laser profilometry, as described in Lo Monte and Felicetti [14], in order to evaluate both maximum and average depths. The moisture front was also measured in one slab only via Ground-Penetrating Radar technique (see [33]).

The regularity of the spalled surface is a very interesting outcome, since it can be inferred that, in substantially uniform heating and loading conditions, the size of spalled splinters is not strictly related to local mechanisms at concrete meso-scale (such as aggregate-to-cement paste interaction). In polypropylene fibre concretes, spalling did not occur and just light scaling was observed at the end of heating. Pictures of some specimens after testing are reported in Fig. 2, while the results are summarized in Table 2.

In Fig. 2 spalling development is sketched on the basis of the observation of concrete debris after testing. In plain concrete, detachments took place probably due to the formation of cracks triggered by compressive thermal stress parallel to the hot face. Pore pressure favoured the unstable propagation of fractures, fostering the violent expulsion of delaminated layers (Fig. 2a). Such mechanisms were partly constrained in steel fibre-reinforced concrete due to the bridging effect provided by steel fibres crossing the cracks. This bridging effect was probably sufficient in slab A of M70S SF40, since spalling did not occur. On 


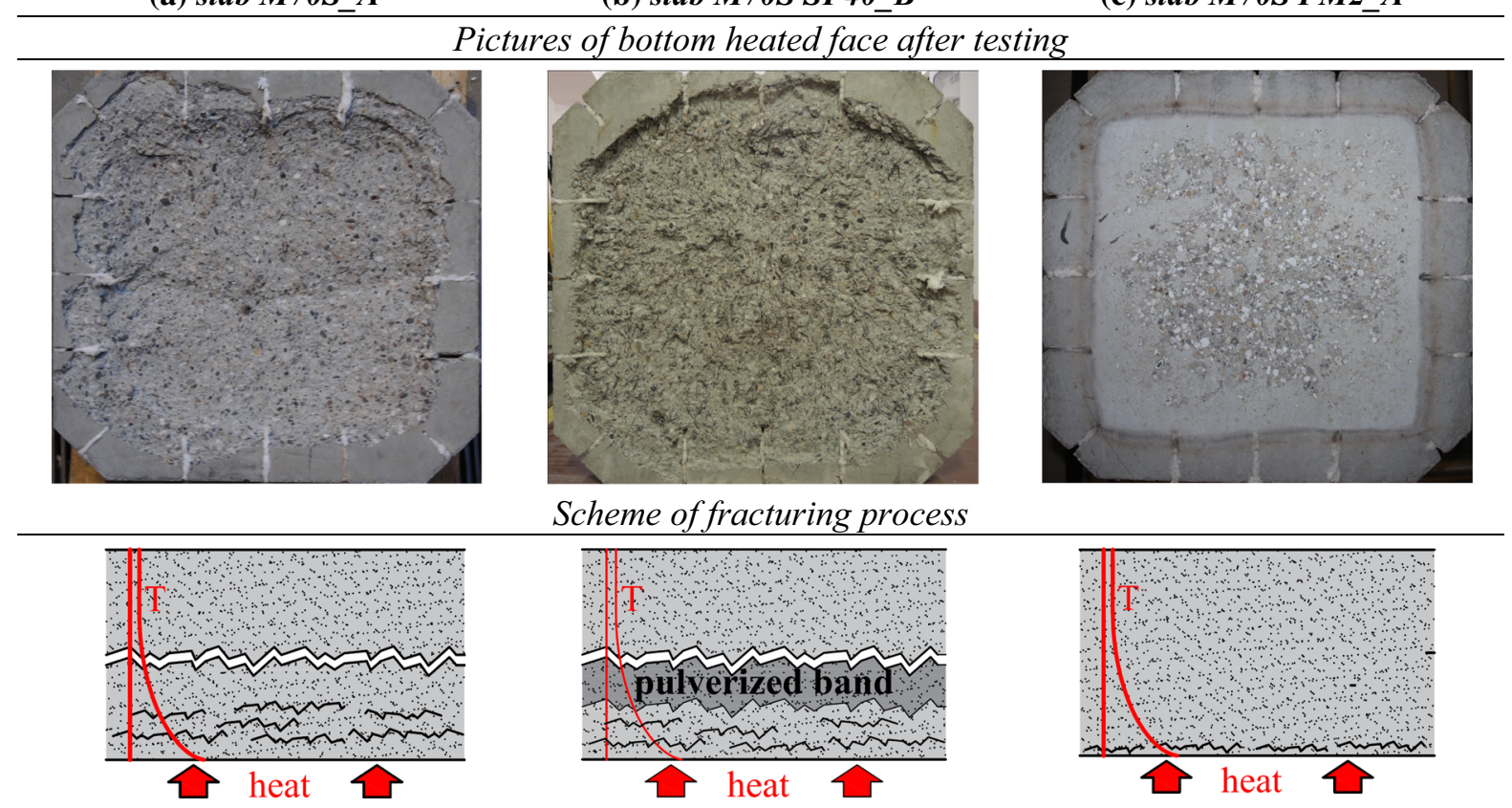

Fig. 2 Bottom heated face of three specimens after testing and scheme of fracturing process in (a) plain, (b) steel and (c) polypropylene fibre concrete slabs

Table 2 Summary of tests and results

\begin{tabular}{|c|c|c|c|c|c|c|c|c|}
\hline \multirow{2}{*}{$\begin{array}{l}\text { Mix designation } \\
\text { Specimen }\end{array}$} & \multicolumn{2}{|c|}{ M70S } & \multicolumn{2}{|c|}{ M70S PM2 } & \multicolumn{2}{|c|}{ M70S PF2 } & \multicolumn{2}{|c|}{ M70S SF40 } \\
\hline & A & B & A & B & A & B & A & B \\
\hline Membrane compression (MPa) & 10 & 10 & 10 & 10 & 10 & 5 & 10 & 10 \\
\hline Fire duration $(\mathrm{min})$ & 35 & 35 & 120 & 120 & 120 & 120 & 110 & 34 \\
\hline Spalling & Yes & Yes & No & No & No & No & No & Yes \\
\hline Time of first spalling event (min) & 19 & 35 & - & - & - & - & - & 34 \\
\hline Avg thickness of first spalled layer (mm) & 10 & 18 & - & - & - & - & - & 23 \\
\hline Temperature at the main fracture $\left({ }^{\circ} \mathrm{C}\right)$ & 225 & 246 & - & - & - & - & - & 238 \\
\hline Avg thickness of following detachments (mm) & 8 & 6 & - & - & - & - & - & - \\
\hline Avg thickness of pulverized band (mm) & - & - & - & - & - & - & - & 16 \\
\hline Avg final spalling depth (mm) & 43 & 42 & - & - & - & - & - & 39 \\
\hline Max final spalling depth (mm) & 60 & 61 & - & - & - & - & - & 51 \\
\hline
\end{tabular}

the other hand, the bridging effect of steel fibre was nullified in slab B by the formation of a "pulverized" band of 15-20 mm thickness, in which concrete was disrupted in the spalling event in powder-like debris (Fig. 2b). The thickness of this layer was assessed by vacuum cleaning the furnace after the test, followed by sieving and weighing of the debris. Moreover, fibres longer than half of their length were protruding from both the remaining slab and the coarse concrete chunks spalled ahead the pulverized band. By cutting and weighing the projecting filaments, an average length of $21 \mathrm{~mm}$ was assessed, namely $60 \%$ of the fibre length (while $25 \%$ would be expected in case of pulled out randomly distributed fibre). 
It is worth noting that the average thickness of the first spalled layer was about 10, 18 and $23 \mathrm{~mm}$ in slabs M70S_A, M70S_B and M70S SF40_B, respectively. The correspondent temperatures at the fracture plane at the onset of the first spalling event $(19,35$ and $34 \mathrm{~min}$, respectively) are within a very narrow range $\left(225-246^{\circ} \mathrm{C}\right)$.

It should be noted that with more severe heating rates and/or thicker specimens (in which thermal stress is higher due to the increased flexural stiffness) spalling can take place also at the very beginning of the test due to the development of higher self-stress.

\subsection{Temperature and pore pressure development}

In Fig. 3 temperature of furnace, hot and cold faces of the slab, and at the 6 internal measurement points (10, 20, 30, 40, 50 and $60 \mathrm{~mm}$ from the heated face) is shown for three specimens, namely plain (M70S_B), steel (M70S SF40_B) and monofilament polypropylene (M70S PM2_B) fibre concrete slabs. Temperature in fibrillated polypropylene fibre concrete (M70S PF2) is not shown, since it is very similar to monofilament polypropylene fibre concrete (M70S PM2). Temperature curves in M70S_B and M70S SF40_B are reported only up to the end of heating (about 34-35 min).

Looking at temperature development, no direct effect of fibre can be recognized, since no particular trend can be clearly identified by comparing the specimens. Though this might have been expected in case of steel fibre, given the little influence on thermal diffusivity [34], it is also confirmed that the mass

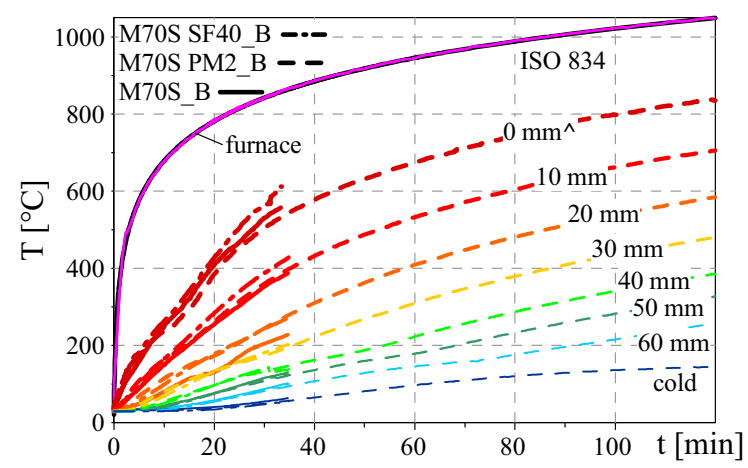

Fig. 3 Plots of temperature of oven, hot and cold faces, and at 6 depths for three slabs, as a function of time. (^Temperature at $0 \mathrm{~mm}$ was not directly measured, but analytically evaluated) transport enhancement allowed by polymeric fibre has little effects on the thermal field.

Pore pressure monitoring along slab thickness is very helpful in understanding the role played by fibre type, especially in case of polypropylene fibre, whose beneficial effects mainly consist in increasing concrete permeability and consequently reducing pore pressure.

Pressure development is reported as a function of time in Fig. 4, where it is clear that the highest values of peak pressure have been reached in the case of steel fibre-reinforced concrete, even higher than in plain concrete.

This can be probably ascribed to the stabilizing effect of steel fibre on crack propagation and, then, on the damage-induced permeability. Such evidence casts some doubt on the use of steel fibre alone for limiting spalling, since the benefits in terms of enhanced mechanical properties may be overcome by the higher pore pressure developed during fire exposure.

The lowest values of pressure have been achieved in the mix with monofilament polypropylene fibre, while slightly higher values have been observed in the case of fibrillated polypropylene fibre. This evidence has been already observed in Lo Monte et al. [4] and can be ascribed to a higher effectiveness of monofilament fibre in increasing concrete permeability, thanks to a higher dispersion in the matrix with respect to fibrillated fibre.

Experimental pressure profiles for different values of fire duration are plotted in Fig. 5a for the reference mix (namely, plain concrete slab B-M70S_B) and for monofilament polypropylene fibre concrete (slab B, M70S PM2_B). Initially, the development of pressure is rather similar, since polypropylene fibres in the hygrally-active region (where significant pressures develop) are not melted yet. After $20 \mathrm{~min}$ of heating, when temperature in the hottest $20 \mathrm{~mm}$ of the slab is higher than the melting temperature of polypropylene (about $160-170{ }^{\circ} \mathrm{C}$ ), the difference between the two mixes becomes evident. In particular pressure quickly rises in plain concrete at $10 \mathrm{~mm}$ from the heated face, leading to relevant pressure gradients. On the other hand, in polypropylene fibre concrete, pressure remains limited and the gradient is far smoother. Moreover, in this latter case the pressure peak tends to follow the fibre melting front and then it is significantly deeper than in plain concrete. 

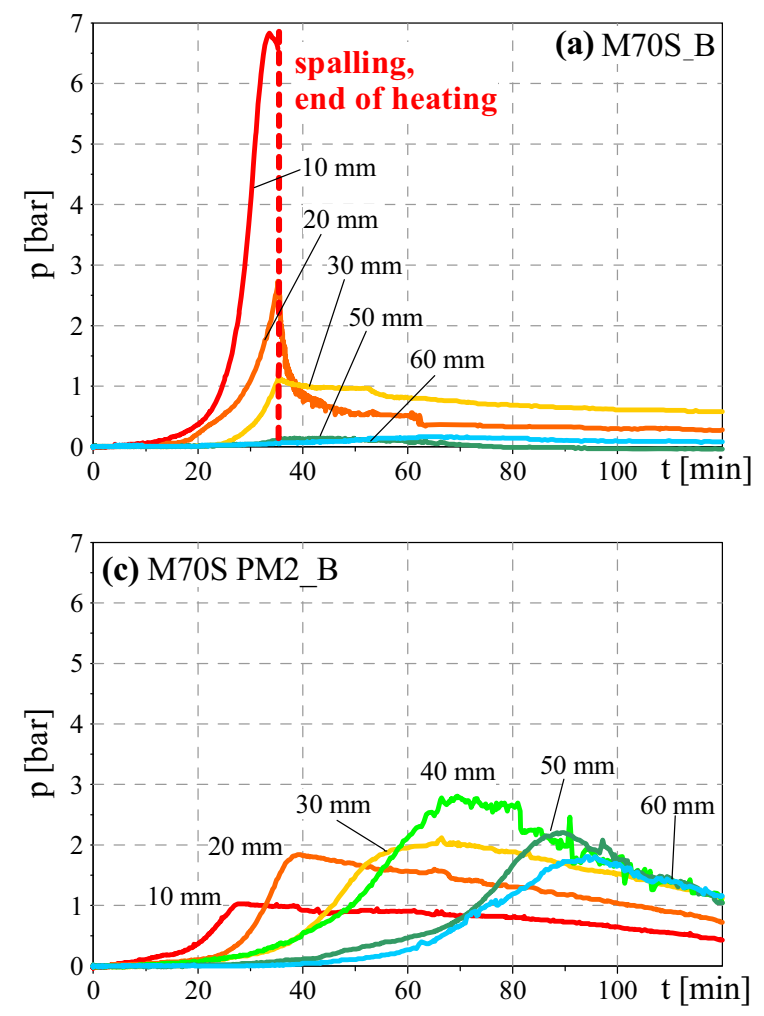
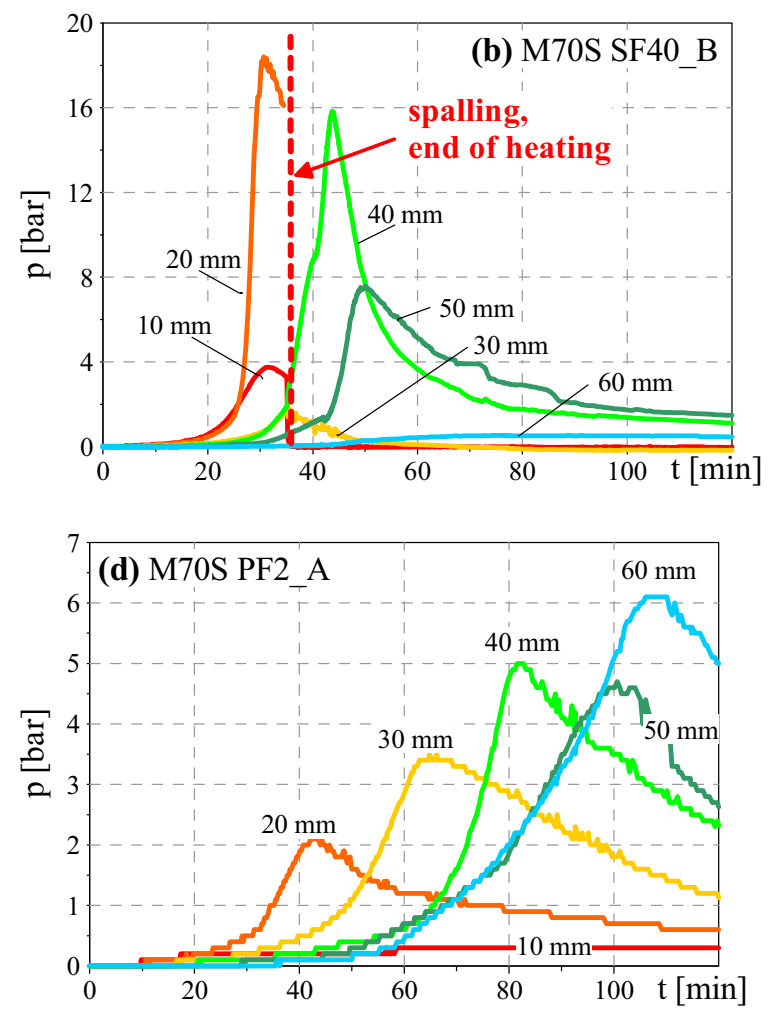

Fig. 4 Plots of pressure at 6 depths for one slab per mix, as a function of time

Steel fibre-reinforced concrete behaved very similarly to plain concrete, with pressure profiles characterized by even sharper gradients. This is reasonably caused by the lower hot permeability (with respect to polypropylene fibre concrete), which limits vapour release, thus forcing pressure to remain concentrated in the hot layer.

In Fig. 5c, d, pressure is reported as a function of temperature, for the two slabs of mix M70S PF2 (fibrillated polypropylene fibre concrete), together with the saturation vapour pressure curve, $P_{\mathrm{SV}}$.

It is worth noting that slab B was subjected to a biaxial membrane compression of $5 \mathrm{MPa}$, while all the other specimens were tested with $10 \mathrm{MPa}$. Looking at the results, it clearly appears that for growing depths, pressure-temperature rate rises (pressure-temperature curve are closer to the saturation vapour pressure curve), and this trend has been observed in all the tests. This is reasonably caused by the increase of the distance with respect to the heated face, from which vapour can be released. Furthermore, it can be observed that pressure-temperature rates and pressure peaks are higher for an external membrane compression of $5 \mathrm{MPa}$ (Fig. 5d) compared to $10 \mathrm{MPa}$ (Fig. 5c), so highlighting the role of external load.

Such result can be explained looking at the numerical analyses reported in Lo Monte and Felicetti [14], which aimed at simulating the experimental test at issue. In particular, it was shown as an external membrane compression of $5 \mathrm{MPa}$ is sufficient to avoid any tensile stress (and, consequently, any crack) in the concrete core because of thermal strain. This means that no significant difference is expected in terms of permeability in the slab core, when the external compression is increased from 5 to $10 \mathrm{MPa}$. On the other hand, the increase of the external compression leads to a more pronounced damage in the hot layer, which is already compressed due to thermal stress. This increased damage, which implies higher cracking and permeability, fostering vapour release and pore pressure reduction. For this reason, higher pore pressure was reached for a confining stress of $5 \mathrm{MPa}$.

It is important to underline that, for lower values of compressive load, the trend is expected to be the opposite. Decreasing the external compression, in fact, 

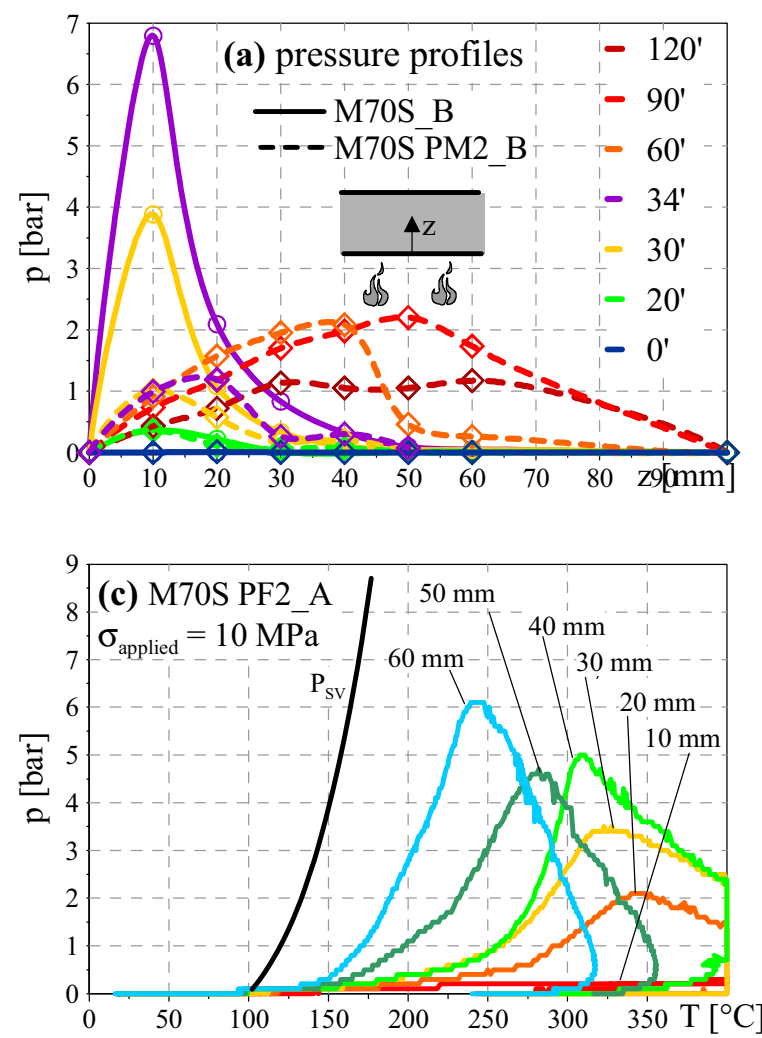

Fig. 5 a Pressure profiles at different fire durations in plain (M70S_B) and monofilament polypropylene fibre (M70S PM2_B) concrete slabs, b vertical displacement at the midpoint of four specimens, and c, d pressure versus temperature in

tensile stress arises in the specimen core and tensile strength can be attained. In such case, cracking occurs and pore pressure release takes place. This means the maximum pressure peaks should be expected for intermediate values of external compression.

Spalling risk and severity, however, should continuously increase with the external load, due to the higher overall damage in the hot layers, as reported in Lo Monte and Felicetti [14] and Miah et al. [28].

\subsection{Flexural behaviour}

The vertical mid-span displacement is shown in Fig. $5 b$ for one slab per mix for the whole fire duration. It is possible to notice that the flexural behaviour can be divided into two stages. In the first phase of heating, sagging deflection takes place because of the thermal dilation of the bottom heated face. Afterwards, when the decay of concrete stiffness
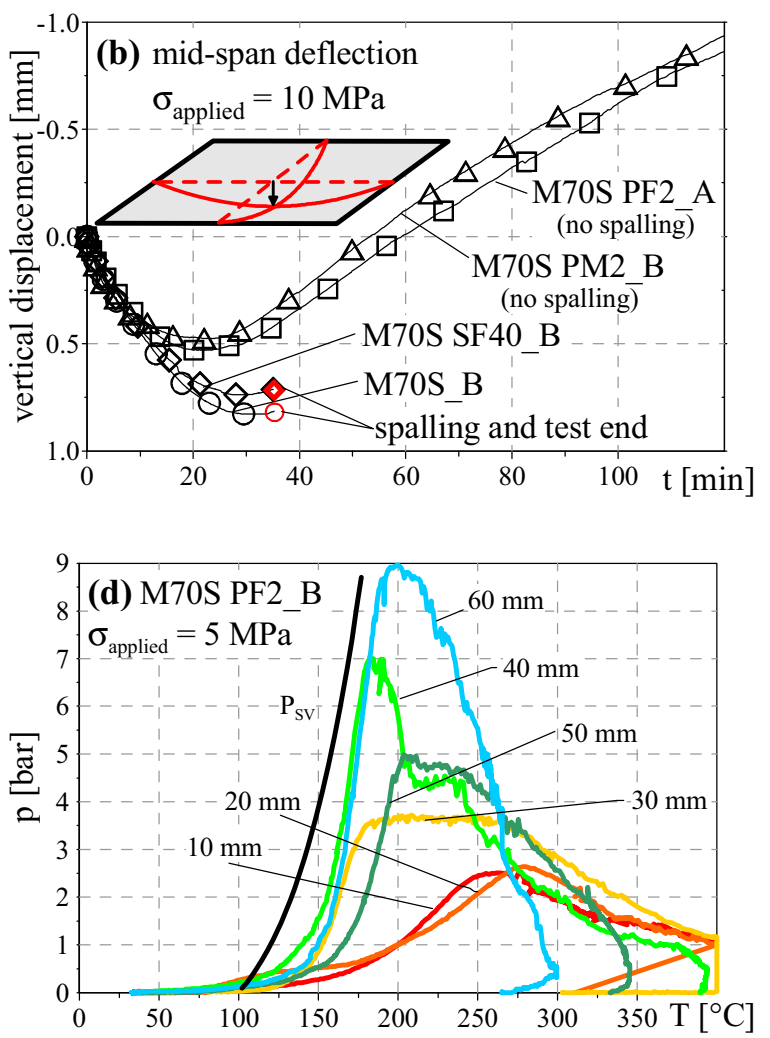

fibrillated polypropylene fibre concrete slabs M70S PF2_A and M70S PF2_B for an applied membrane stress of 10 and $5 \mathrm{MPa}$, respectively

in the hot layer becomes sizable, hogging deflection occurs due to the rise of the stiffness centre, which translates into a negative eccentricity for the external load (constantly applied at the mid-plane). Thus, in the second phase, the displacement rate changes sign (after about 25-30 min of fire duration). Obviously, hogging deflection during heating can occur only if a significant external load is applied.

Looking at Fig. 5b, no remarkable difference can be observed between plain and steel fibre-reinforced concrete, while if monofilament or fibrillated polypropylene fibre is added, hogging deflection occurs significantly earlier.

In particular, the maximum sagging deflection is $700-800 \mu \mathrm{m}$ for plain and steel fibre-reinforced concretes, while is $400-500 \mu \mathrm{m}$ in the case of polypropylene fibre concretes. This result implies that polypropylene fibre leads to a more pronounced increase of concrete deformability with temperature, 
so fostering the effect of the external load (hogging deflection).

The concretes at issue have been extensively studied in a previous experimental campaign focused on the compressive behaviour of concrete cylinders at high temperature and in residual conditions, proving that the decay of elastic modulus as a function of temperature is just slightly influenced by the addition of polypropylene fibre $[35,36]$. This suggests that the difference in the flexural behaviour is probably caused by a higher transient thermal strain occurring when polypropylene fibre is added (as observed also in [11]).

\section{Conclusions}

A novel experimental setup for investigating fire spalling phenomenon in concrete has been designed at Politecnico di Milano based on slabs heated at the bottom, while subjected to external biaxial membrane compression.

Taking advantage of this facility, the goal of the presented experimental research is to study the main effects brought in by fibre type in concrete sensitivity to spalling. To this aim, four mixes have been designed, consisting in High-Performance Concretes $\left(f_{\mathrm{c}} \approx 60 \mathrm{MPa}\right.$, with silico-calcareous aggregate) differing only for the presence of monofilament or fibrillated polypropylene, or steel fibres. Two slabs per mix were cast.

Spalling occurred in both plain concrete slabs, and in one of the two steel fibre-reinforced specimens, while the addition of polypropylene-either monofilament or fibrillated-fibre allowed to avoid any detachment for the whole fire duration (100-120 min).

The spalling process started in all the cases with a very violent event involving all the heated area. After cooling, the spalled layer appeared rather homogeneous, corroborating the idea that, in substantially uniform heating and loading conditions, spalling phenomenon is not strictly related to local mechanisms regarding aggregate-to-cement paste interaction and that a more general explanation can be given based on temperature, pressure and stress fields.

The development of the thermal field was rather similar among the specimens. This evidence suggests a limited role played by moisture transport phenomena in concrete thermal behaviour. (Polypropylene fibre concretes have higher permeability than plain concrete due to fibre, but similar thermal diffusivity). Moreover, steel fibres are known to not significantly influence concrete thermal conductivity.

The highest values of peak pressure were reached in steel fibre-reinforced concrete, even higher than in plain concrete, probably because of a more stable crack propagation. This evidence should discourage the use of steel fibre alone with the aim of reducing spalling risk, since the induced increase in pore pressure can even offset the advantage brought in by the improved tensile toughness. In the case at hand, the beneficial effect of steel fibre was nullified by the formation of a pulverized band of concrete, which zeroed any bridging effect of the fibres anchored in the band.

On the other hand, far lower values of pressure have been observed in polypropylene fibre concrete, thanks to the increase of permeability allowed by fibre melting. In particular monofilament polypropylene fibre proved to be more effective than fibrillated polypropylene fibre in reducing pore pressure.

Plain and steel fibre-reinforced concretes experienced pressure profiles characterized by sharper gradients, reasonably due to their lower permeability, this limiting vapour release and forcing the pressure to remain concentrated in the hot layer.

As regards the mechanical behaviour, monitoring the out-of-plane deflection revealed as the introduction of polypropylene fibre probably leads to higher transient thermal strain compared to plain or steel fibre-reinforced concrete (this possibly smoothing down thermal stress).

Acknowledgements The Authors are grateful to Italcementi S.p.A.-HeidelbergCement Group, Global Product Innovation Department (Bergamo, Italy) for the design of the concrete mixes and the useful contribution in preparing the specimens. Fondazione Lombardi Ingegneria (Minusio, Switzerland) is thanked for the financial support given to this research project. The logistic and technical support of LPM (Laboratory of Material and Structural Testing) at Politecnico di Milano is also acknowledged. Finally, the authors wish to thank Alessandra Piovan, Gabriele Scaciga and Haibin Zhi, who actively contributed to this study in partial fulfilment of their MS degree requirements at Politecnico di Milano.

\section{Compliance with ethical standards}

Conflict of interest The first two authors are members of RILEM Committee TC 256-SPF "Spalling of concrete due to fire: testing and modelling". 
Open Access This article is licensed under a Creative Commons Attribution 4.0 International License, which permits use, sharing, adaptation, distribution and reproduction in any medium or format, as long as you give appropriate credit to the original author(s) and the source, provide a link to the Creative Commons licence, and indicate if changes were made. The images or other third party material in this article are included in the article's Creative Commons licence, unless indicated otherwise in a credit line to the material. If material is not included in the article's Creative Commons licence and your intended use is not permitted by statutory regulation or exceeds the permitted use, you will need to obtain permission directly from the copyright holder. To view a copy of this licence, visit http://creativecommons.org/licenses/by/4.0/.

\section{References}

1. Fib (2008) Bulletin 46: fire design of concrete structuresstructural behaviour and assessment. International Federation for Structural Concrete (fib), Lausanne

2. Khoury GA, Anderberg Y (2000) Concrete spalling review. Fire Safety Design, report submitted to the Swedish National Road Administration, Sweden

3. Felicetti R, Lo Monte F, Pimienta P (2017) A new test method to study the influence of pore pressure on fracture behaviour of concrete during heating. Cem Concr Res 94:13-23

4. Lo Monte F, Felicetti R, Miah Md. J (2019) The Influence of pore pressure on fracture behaviour of normal-strength and high-performance concretes at high temperature. Cem Concr Compos

5. Fib (2007) Bulletin 38: fire design of concrete structuresmaterials, structures and modelling. International Federation for Structural Concrete (fib), Lausanne

6. Fu Y, Li L (2010) Study on mechanism of thermal spalling in concrete exposed to elevated temperatures. Mater Struct 44:361-376

7. Khoury GA (2000) Effect of fire on concrete and concrete structures. Prog Struct Mater Eng 2:429-447

8. Khoury GA (2008) Polypropylene fibres in heated concrete. Part 2: pressure relief mechanisms and modelling criteria. Mag Concr Res 60(3):189-204

9. Dal Pont S, Dupas A, Ehrlacher A, Colina H (2005) An experimental relationship between complete liquid saturation and violent damage in concrete submitted to high temperature. Mag Concr Res 57(8):455-461

10. Kalifa P, Menneteau FD, Quenard D (2000) Spalling and pore pressure in HPC at high temperatures. Cem Concr Res 30:1915-1927

11. Huismann S, Weise F, Meng B, Schneider U (2012) Transient strain of high strength concrete at elevated temperatures and the impact of polypropylene fibers. Mater Struct 45:793-801

12. Pistol K, Weise F, Meng B, Diederichs U (2014) Polypropylene fibres and micro cracking in fire exposed concrete. Adv Mater Res 897:284-289
13. Toropovs N, Lo Monte F, Wyrzykowski M, Weber B, Sahmenko G, Vontobel P, Felicetti R, Lura P (2015) Realtime measurements of temperature, pressure and moisture profiles in High-Performance Concrete exposed to high temperatures during neutron radiography imaging. Cem Concr Res 68:166-173

14. Lo Monte F, Felicetti R (2017) Heated slabs under biaxial compressive loading: a test set-up for the assessment of concrete sensitivity to spalling. Mater Struct 50(4):192

15. Krzemien K, Hager I (2015) Assessment of concrete susceptibility to fire spalling: a report on the state-of-the-art in testing procedures. Procedia Eng 108:285-292

16. Mindeguia JC (2009) Contribution Expérimental a la Compréhension des risqué d'Instabilité Thermiques des Béton. Ph.D. Thesis, Université de Pau et des Pays de l'Adour, France

17. Mindeguia JC, Pimienta P, Noumowé A, Kanema M (2010) Temperature, pore pressure and mass variation of concrete subjected to high temperature-experimental and numerical discussion on spalling risk. Cem Concr Res 40:477-487

18. Lo Monte F, Gambarova PG (2015) Corner spalling and tension stiffening in heat-damaged $\mathrm{R} / \mathrm{C}$ members: a preliminary investigation. Mater Struct 48:3657-3673

19. Hertz K, Sørensen L (2005) Test method for spalling of fire exposed concrete. Fire Saf J 40:466-476

20. Tanibe T, Ozawa M, Kamata R, Rokugo K (2014) Steel ring-based restraint of HSC explosive spalling in high temperature environments. J Struct Fire Eng 5(3):239-250. https://doi.org/10.1260/2040-2317.5.3.239

21. Connolly R (1995) The spalling of concrete in fires. Ph.D. Thesis. The University of Aston in Birmingham

22. Heel A, Kusterle W (2004) Die Brandbeständigkeit von Faser-, Stahl- und Spannbeton [Fire resistance of fiber-reinforced, reinforced, and prestressed concrete] (in German), Tech. Rep. 544, Bundesministerium für Verkehr, Innovation und Technologie, Vienna

23. Sjöström J, Lange D, Jansson R, Boström L (2012) Directional dependence of deflections and damages during fire tests of post-tensioned concrete slabs. In: Proceedings of the 7th international conference on structures in fire-SIF' 12, June 6-8, 2012, Zurich, Switzerland, pp 589-598

24. Boström L, Wickström U, Adl-Zarrabi B (2007) Effect of specimen size and loading conditions on spalling of concrete. Fire Mater 31:173-186

25. Jansson R, Boström L (2008) Spalling of concrete exposed to fire. SP Technical Research Institute of Sweden, Borås

26. Carré H, Pimienta P, La Borderie C, Pereira F Mindeguia JC (2013) Effect of compressive loading on the risk of spalling. In: Proceedings of the 3rd international workshop on concrete spalling due to fire exposure, September 25-27, 2013, Paris, France, p 01007

27. Rickard I, Bisby L, Deeny S, Maluk C (2016) Predictive testing for heat induced spalling of concrete tunnels-the influence of mechanical loading. In: Proceedings of the 9th international conference structures in fire 2016-SIF' 16, June 8-10, 2016, Princeton, USA, pp 217-224

28. Miah MdJ, Lo Monte F, Felicetti R, Carré H, Pimienta P, Borderie CL (2016) Fire spalling behaviour of concrete: role of mechanical loading (uniaxial and biaxial) and cement type. Key Eng Mater 711:549-555 
29. Rossino C, Lo Monte F, Cangiano S, Felicetti R, Gambarova PG (2013) Concrete spalling sensitivity versus microstructure: preliminary results on the effect of polypropylene fibres. In: Proceedings of the 3rd international workshop on concrete spalling due to fire exposure, September 25-27, Paris, France. https://doi.org/10.1051/ matecconf/20130602002

30. Rossino C, Lo Monte F, Cangiano S, Felicetti R, Gambarova PG (2015) HPC subjected to high temperature: a study on intrinsic and mechanical damage. In: Proceedings of the 10th international symposium on high performance concrete-innovation and utilization-HPC 2014, Beijing, China, September 16-18, 2014, Key Engineering Materials, vols. 629-630, pp 239-244

31. Bayasi Z, McIntyre M (2002) Application of fibrillated polypropilene fibers for restraint of plastic shrinkage cracking in silica fume concrete. Mater J 99(4):337-344

32. Lo Monte F, Felicetti R (2015) Experimental methods for spalling monitoring during and after a fire. In: Proceedings of the 4th international workshop on concrete spalling due to fire exposure, Leipzig, Germany, 8-9 Oct 2015
33. Lo Monte F, Lombardi F, Felicetti R, Lualdi M (2017) Ground-penetrating radar monitoring of concrete at high temperature. Constr Build Mater 151(1):881-888

34. Felicetti R, Ferrara L (2008) The effect of steel fibre on concrete conductivity and its connection to on-site material assessment. In: Proceedings of 7th RILEM international symposium on fibre reinforced concrete, Chennai, India, pp 525-536

35. Lo Monte F (2014) Reinforced concrete in fire: from materials behaviour to spalling sensitivity and structural modelling. Ph.D. Thesis, Structural Seismic and Geotechnical Engineering, Politecnico di Milano

36. Rossino C (2014) Intrinsic damage and spalling sensitivity of concrete subjected to high temperature. Ph.D. Thesis, Structural Seismic and Geotechnical Engineering, Politecnico di Milano

Publisher's Note Springer Nature remains neutral with regard to jurisdictional claims in published maps and institutional affiliations. 